\title{
Molecular analysis and literature-based hypothesis of an immunonegative prostate small cell carcinoma causing ectopic ACTH syndrome
}

\author{
Maki Takeuchi ${ }^{1)}$, Junichiro Sato ${ }^{1)}$, Katsunori Manaka ${ }^{1)}$, Mariko Tanaka ${ }^{2)}$, Hotaka Matsui ${ }^{3)}$, Yusuke Sato ${ }^{3)}$, \\ Haruki Kumes), Masahisa Fukayama'), Taroh Iiri'1),4), Masaomi Nangaku' ${ }^{1)}$ and Noriko Makita ${ }^{1)}$
}

\author{
1) Department of Nephrology and Endocrinology, The University of Tokyo, Tokyo, Japan \\ 2) Department of Pathology, The University of Tokyo, Tokyo, Japan \\ 3) Department of Urology, The University of Tokyo, Tokyo, Japan \\ 4) Department of Pharmacology, St. Marianna University School of Medicine, Kawasaki, Japan
}

\begin{abstract}
Ectopic ACTH syndrome (EAS) due to a prostate small cell carcinoma (SCC) is very rare with only 26 cases reported to date and has a poor prognosis. We here describe another case of this disorder that was clinically typical based on prior reports as it showed hypercortisolemia and severe hypokalemia with multiple metastasis. However, our current case of prostate SCC causing EAS is the first to display negative immunostaining for ACTH despite detectable POMC mRNA expression in the primary lesion. ACTH immunonegativity is thought to be associated with a more aggressive disease course and a poorer prognosis although there are few studies of the underlying mechanisms. We explored two possibilities for this finding in our current patient: aberrant POMC processing prevented immunodetection with an anti-ACTH antibody; and the ACTH content per cell was below the threshold for immunodetection due to its rapid secretion or low synthesis. The aberrant processing theory was thought to be less likely because of immunonegative findings even using anti-POMC/ACTH antibodies. As the plasma ACTH levels in our patient were comparable with those reported for previous immunopositive prostate EAS cases, we speculated that the depletion of ACTH may be caused not only by rapid secretion but also by low production levels as a sign of de-differentiation. De-differentiation may therefore explain the mechanism underlying the negative correlation between immunoreactivity for ACTH in EAS and disease aggressiveness. We believe that our present findings will be of use in future prospective studies aimed at confirming the mechanism of immunonegativity.
\end{abstract}

Key words: Ectopic ACTH syndrome, Prostate small cell carcinoma, Immunostaining, Proopiomelanocortin (POMC), De-differentiation

\section{ECTOPIC ADRENOCORTICOTROPIC HORMONE} (ACTH) SYNDROME (EAS) is characterized by hypercortisolism due to the hypersecretion of non-pituitary ACTH-secreting tumor, which leads to Cushing's syndrome [1]. EAS accounts for approximately $10 \%$ of all cases of Cushing's syndrome [2]. These tumors usually originate from a lung small cell carcinoma (SCC), but can also be initiated from the larynx, esophagus, urinary bladder, and urogenital system [3, 4]. Prostate SCC causing Cushing's syndrome is rare however with only 26 published cases to date [5]. In addition, SCC is an unusual variant of prostate carcinoma. Extrapulmonary

Submitted Dec. 18, 2018; Accepted Feb. 25, 2019 as EJ18-0563 Released online in J-STAGE as advance publication Mar. 28, 2019 Correspondence to: Noriko Makita, Department of Nephrology and Endocrinology, The University of Tokyo, 7-3-1 Hongo, Bunkyoku, Tokyo 113-8655, Japan.

E-mail: norimaki-tky@umin.ac.jp
SCC (EPSCC) can occur in a variety of sites with the incidence in North America approximated at $0.1 \%$ to $0.4 \%$ [6]. Among the possible sites for EPSCC, approximately $10 \%$ of cases arise in the prostate $[7,8]$ and are associated with a poor median survival of 10 months [9].

We experienced a case of EAS caused by prostate SCC with negative immunostaining for ACTH. To our knowledge, this is the first instance of a false-negative ACTH immunohistochemistry (IHC) finding associated with this condition. Prior studies have presented various possible explanations for ACTH immunonegativity in tumors causing EAS including corticotropin releasing hormone $(\mathrm{CRH})$ instead of ACTH production [10, 11], a predominance of ACTH precursors that are not immunoreactive to a particular anti-ACTH antibody [12], excessive hormone secretion rates leading to a reduced storage of ACTH [13], and a relatively low level of ACTH synthesis per tumor cell in comparison to pitui- 
tary or carcinoid tumors [14]. Notably however, few studies have been conducted to elucidate the mechanisms underlying these possibilities, especially the latter two. In our present EAS case study, we investigated the possible mechanisms underlying the negative immunostaining for ACTH using alternative antibodies and literaturebased analysis.

\section{Materials and Methods}

\section{$R N A$ extraction and $R T-P C R$}

RNA was extracted from paraffin-embedded specimens using the RecoverAll Total Nucleic Acid Isolation Kit (Life Technologies, Carlsbad, CA) in accordance with the manufacturer's instructions. The sampled RNA was reverse transcribed using ReverTra Ace qPCR RT Master Mix with gDNA Remover (TOYOBO, Osaka, Japan) and RT-PCR was then performed using the following primers: sense primer 5'-CAGCCAGTGTCAGG ACCTCACC-3', antisense primer 5'-GGGGCCCTCGTC CTTCTTCTCG-3' for human proopiomelanocortin (POMC), sense primer 5'-GCACCCTCAGCCCTTGGA TTTC-3', antisense primer 5'-AATCTCCATGAGTTTCC TGTTGC-3' for human CRH, and sense primer 5'-TCGT GCGTGACATTAAGGAG-3', antisense primer 5'-AGC ACTGTGTTGGCGTACAG-3' for human $\beta$-actin. The amplification program for POMC and $\beta$-actin comprised 40 cycles of $30 \mathrm{~s}$ at $94^{\circ} \mathrm{C}, 1 \mathrm{~min}$ at $58^{\circ} \mathrm{C}$ and $30 \mathrm{~s} 72^{\circ} \mathrm{C}$ with a final extension for $10 \mathrm{~min}$ at $72^{\circ} \mathrm{C}$, and for $\mathrm{CRH}$ included 40 cycles of $30 \mathrm{~s}$ at $94^{\circ} \mathrm{C}, 1 \mathrm{~min}$ at $65^{\circ} \mathrm{C}$ and 30 $\mathrm{s}$ min $72^{\circ} \mathrm{C}$ and a final extension for $10 \mathrm{~min}$ at $72^{\circ} \mathrm{C}$. We used HeLa cells as a positive control for CRH mRNA as they have been reported previously to express this transcript [15].

\section{Immunohistochemistry}

Immunohistochemistry (IHC) analysis was performed using Bench Mark ULTRA (Roche Diagnostics, Tokyo, Japan), in accordance with the manufacturer's instructions. We used two different mouse monoclonal antibodies to detect POMC/ACTH, B427 (sc-57021) and F-3 (sc-373878) (Santa Cruz Biotechnology, Santa Cruz, CA). These are specific for the N-terminal sequence of human ACTH residues 1-24 and an internal peptide sequence within mouse POMC, respectively. To detect $\mathrm{ACTH}$, we used a mouse monoclonal antibody, Dako clone 02A3 (M3501) (Agilent Technologies Japan, Hachioji, Tokyo). This antibody is specific for the Cterminal sequence of human ACTH residues 24-39. As an immunopositive control for ACTH, we used paraffinembedded specimens of metastatic lymph node from a bronchial carcinoid patient showing EAS, which we experienced previously. As an immunonegative control, we used the lung alveoli attached to the resected metastatic lymph node of the bronchial carcinoid patient.

\section{Informed consent}

The analyses of the patients' tissue samples were approved by the Institutional Review Board of the University of Tokyo, and informed consent was obtained from the individuals in this study.

\section{Results}

\section{Case presentation}

A 75-year old man was admitted to hospital with profound body weight loss, appetite loss and progressive back and hip pain. He had a history of chronic obstructive pulmonary disease, antithrombin III deficiency, and deep venous thrombosis. A subsequent physical examination revealed a blood pressure of $126 / 78 \mathrm{mmHg}$, a heart rate of 72/min, weight of $60.3 \mathrm{~kg}$, and height of 167 $\mathrm{cm}$. He showed pitting edema in both legs, hyperpigmentation, thinning of the skin and severe muscle weakness of the limbs. A digital rectal examination revealed a hard irregular prostate gland. Computed tomography of the abdomen revealed a $40 \mathrm{~mm}$, heterogeneously enhanced lobulated lesion in the prostate, with tumor invasion of the liver and bone, and engagement of the lymph nodes along the bilateral internal iliac artery and around the abdominal aorta. The Pro GRP and neuron-specific enolase (NSE) tumor markers were significantly elevated (Pro GRP 74,000 pg/mL; reference interval 0-80.9 $\mathrm{pg} / \mathrm{mL}$, NSE $66.9 \mathrm{ng} / \mathrm{mL}$; reference interval 0-16.3 $\mathrm{ng} / \mathrm{mL}$ ) although the prostate specific antigen (PSA) level was within the normal reference range (PSA 0.70 $\mathrm{ng} / \mathrm{mL}$; reference interval, $0-4 \mathrm{ng} / \mathrm{mL}$ ). Laboratory tests on admission revealed severe hypokalemia ( $\mathrm{K} 1.8$ $\mathrm{mEq} / \mathrm{L}$ ), hyperglycemia, and leukocytosis (WBC 16,300/ $\mu \mathrm{L})$. Hormonal evaluations revealed markedly elevated plasma ACTH $(225.5 \mathrm{pg} / \mathrm{mL}$, reference interval, 7.2$63.3 \mathrm{pg} / \mathrm{mL})$, serum cortisol $(54.7 \mu \mathrm{g} / \mathrm{dL}$; reference interval, 6.4-21.0 $\mu \mathrm{g} / \mathrm{dL})$ and urinary free cortisol $(544.4 \mu \mathrm{g} /$ day, reference interval, 11.2-80.3 $\mu \mathrm{g}$ /day). Overnight 1 $\mathrm{mg}$ and $8 \mathrm{mg}$ dexamethasone suppression tests were both positive (ACTH and cortisol; $220.50 \mathrm{pg} / \mathrm{mL}$ and 59.9 $\mu \mathrm{g} / \mathrm{dL}, 146.10 \mathrm{pg} / \mathrm{mL}$ and $51.5 \mu \mathrm{g} / \mathrm{dL}$ after suppression, respectively). Transperineal biopsied specimens of the prostate in our patient indicated intermediate SCC cell variants with small component of acinar adenocarcinoma. Immunohistochemical staining was strongly positive for CD56 and synaptophysin, weakly positive for chromogranin A, but negative for PSA in the component of SCC (Fig. 1a-e). Surprisingly however, ACTH immunostaining with a commercial antibody (Dako clone 02A3) was clearly negative (Fig. 1f), contrary to positive 


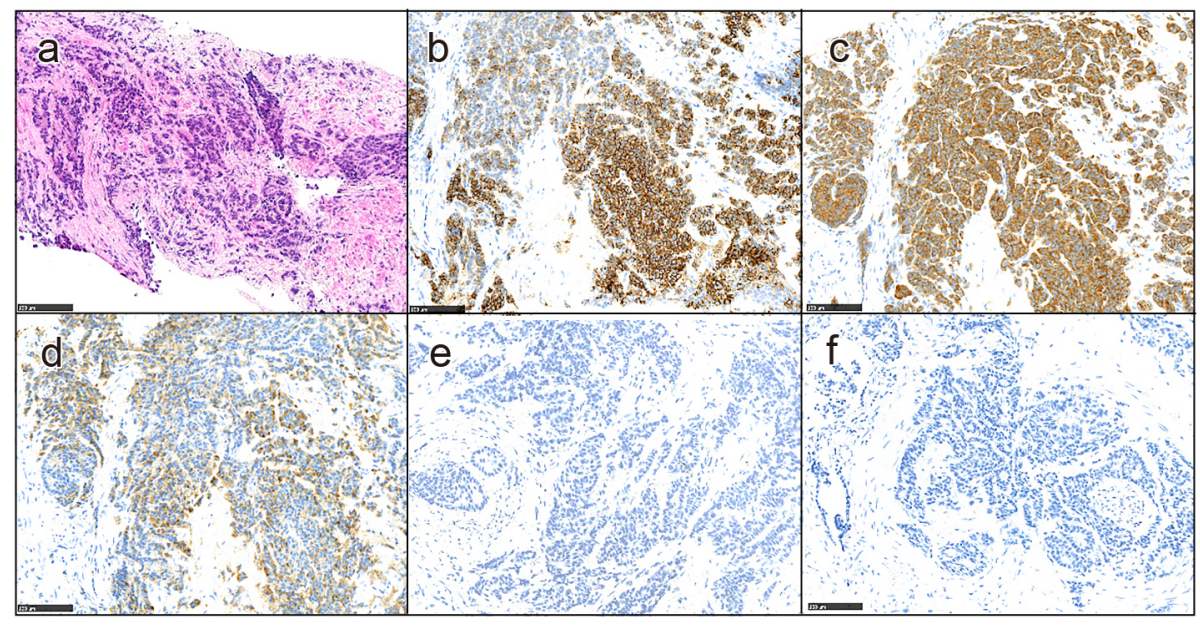

Fig. 1 Hematoxyline-Eosine staining and immunohistochemistry for the biopsied prostate samples

The cells showed strongly positive staining for CD56 and synaptophysin, and weakly positive staining for chromogranin A, but negative staining for PSA and ACTH. (a) Hematoxyline-Eosine staining $(\times 200)$, (b) CD56 $(\times 200)$, (c) synaptophysin $(\times 200)$, (d) chromogranin A $(\times 200)$, (e) PSA $(\times 200)$, (f) ACTH $(\times 200)$

staining to an internal control (data not shown). Although ACTH production was not immunohistochemically detectable in our patient, a clinical diagnosis of EAS due to prostate SCC was made. An octreotide loading test was performed to explore the therapeutic options for controlling hypercortisolemia but failed in the suppression of the ACTH levels. The tumor was found to be unresectable and the poor condition of the patient prevented the use of chemotherapy. He opted for supportive care and was treated with metyrapone and given pain relief. His hypokalemia was temporally controlled with metyrapone and supplementation with potassium. The metyrapone treatment had to be discontinued before normalization of hypercortisolemia however because of swallowing difficulties. The patient died four days after his transfer to the palliative hospital.

\section{Detection of ACTH and CRH in our current EAS case by RT-PCR and immunohistochemistry}

The histological findings for the biopsied prostate specimens from our study patient were consistent with prostate SCC. As indicated above, the immunohistochemical staining for ACTH was clearly negative (Fig. 1f). We first suspected that Cushing's syndrome might have been caused by secretion of not ACTH but CRH from the prostate tumor. It was subsequently found that proopiomelanocortin (POMC) mRNA, but not $\mathrm{CRH}$ transcripts, was expressed in the prostate of our current case whereas CRH mRNA was expressed in HeLa cells (Fig. 2). The reason for the discrepancy between POMC mRNA positivity and negative immunostaining for ACTH remained elusive however. We speculated that so called "big ACTH" may have been present in our current

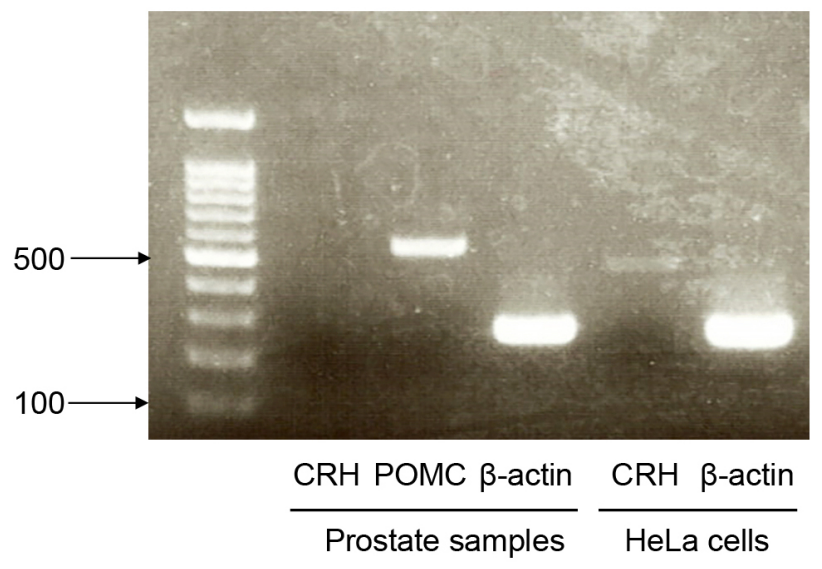

Fig. 2 Results of RT-PCR using the biopsied prostate samples and HeLa cells

The analysis by RT-PCR showed not CRH mRNA expression but POMC mRNA expression in prostate biopsied samples. CRH mRNA expression was expressed in HeLa cells.

patient due to a previously described aberrant and dominant prohormone processing of POMC to ACTH in the tumor $[12,16]$. It has also been reported that the levels of ACTH precursors but not ACTH itself correlate with those of plasma cortisol in patients with EAS [17]. If our current patient's specimens were positive by anti-ACTH/ POMC antibodies, aberrant prohormone processing might be a reason for immunonegativity.

First of all, we determined the optimal concentration of anti-POMC/ACTH antibodies, B427 and F-3, using a positive control (Fig. 3a, b) and a negative control (data not shown). We subsequently performed immunohisto- 


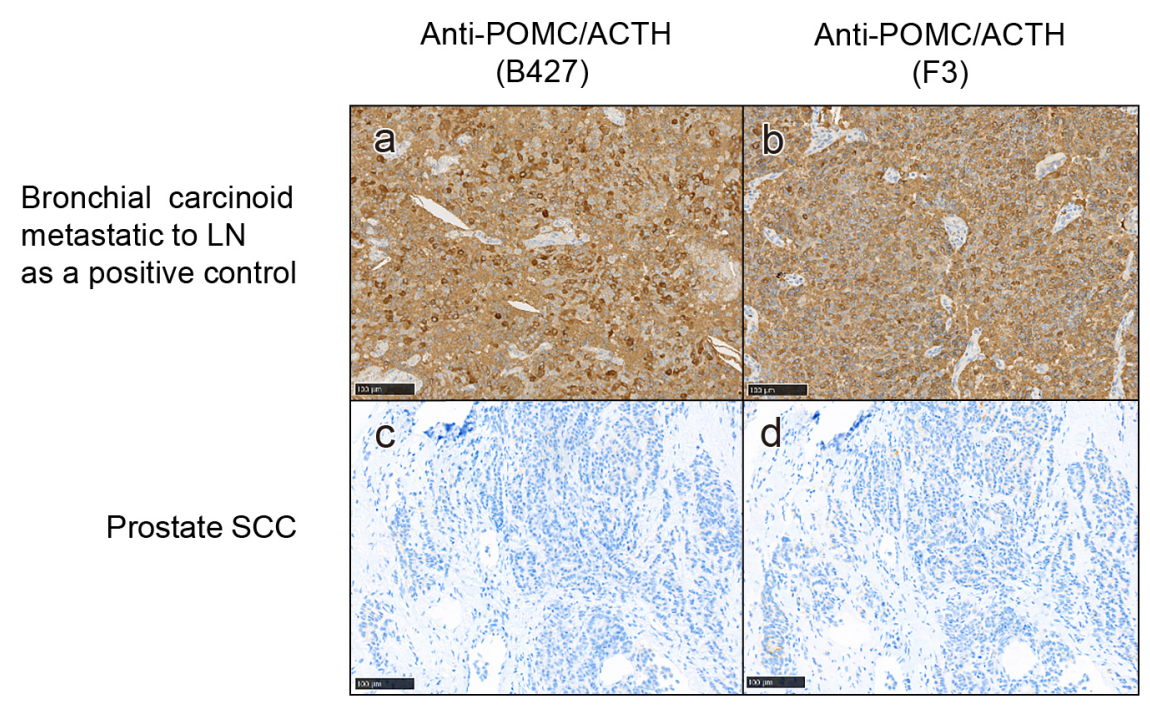

Fig. 3 Immunohistochemical analyses for POMC/ACTH using the biopsied prostate samples

The bronchial carcinoid metastatic to lymph node showed positive staining by anti-POMC/ACTH antibodies (B427) (1:500) (a) and (F-3) $(1: 1,000)(b)$. Prostate biopsied samples showed almost negative staining by anti-POMC/ACTH antibodies (c, d)

chemical staining of biopsied prostate specimens from our current study case. There was however little definite immunoreactivity with either antibody (Fig. 3c, d). Although we did not analyze a homogenate sample using HPLC for inquiry as to the existence of "big ACTH", aberrant prohormone processing might not be a main reason for ACTH immunonegativity in our patient.

Several previous reports have attributed such a discrepancy to a rapid ACTH secretion rate [14, 18-25]. If this theory was applicable to our present immunonegative case, we speculated that the plasma ACTH levels would be higher than those found in prior immunopositive patients, provided that the synthesis rates of this protein were comparable. We therefore investigated this possibility.

\section{Review of the plasma ACTH levels and immunoreactivity in prior cases of prostate SCC causing EAS}

We reviewed the correlation between the plasma levels and immunoreactivity for ACTH in all of the 26 previously published cases of prostate SCC causing EAS. We found however that IHC detection of ACTH had only been performed in 9 of these prior cases (Table 1), all of which showed immunopositivity. It was notable however that the patient described by Ghali and colleagues was immunonegative for ACTH in the metastatic liver and adrenal gland but immunopositive in the primary prostate SCC, metastatic bone and lymph node [26]. This case with immunonegative metastatic sites also showed a relatively low plasma level of ACTH $(180 \mathrm{pg} / \mathrm{mL})$, which seems to be incompatible with a rapid secretion theory with similar synthesis rate. The patient described by Elston et al. showed a detectable plasma CRH level, suggesting a possible secretion of CRH from the tumor and that the plasma ACTH level might have been affected by both tumor-derived and pituitary-derived ACTH [5]. Excluding these two cases, we compared our case to 6 immunopositive cases for which the ACTH levels were reported. Among these 7 cases, the plasma ACTH level in our current case $(225.5 \mathrm{pg} / \mathrm{mL})$ was found to be lower than the median (Fig. 4). If ACTH production rate is comparable between in our case and in the immunopositive cases and ACTH immunonegativity in our case is caused by rapid secretion rate, the plasma ACTH level in our case might be higher than those of immunopositive cases. However, it was not the case. We speculated therefore that negative immunostaining for ACTH in our case might be caused not only by accelerated secretion but also by a relatively lower synthesis of POMC/ACTH per tumor cell, resulting in a concentration of protein that is below the threshold of detection by IHC.

\section{Discussion}

We here describe a case of Cushing's syndrome resulting from a prostate SCC lesion with a negative immunostaining result for ACTH despite detectable POMC mRNA expression. This discrepancy might be caused by rapid ACTH secretion and low ACTH production, reflecting de-differentiation. Prostate SCC causing EAS is an extremely rare condition with only 26 prior cases described to date [5], which enabled us to review the data for each patient in considerable detail (Table 1). 


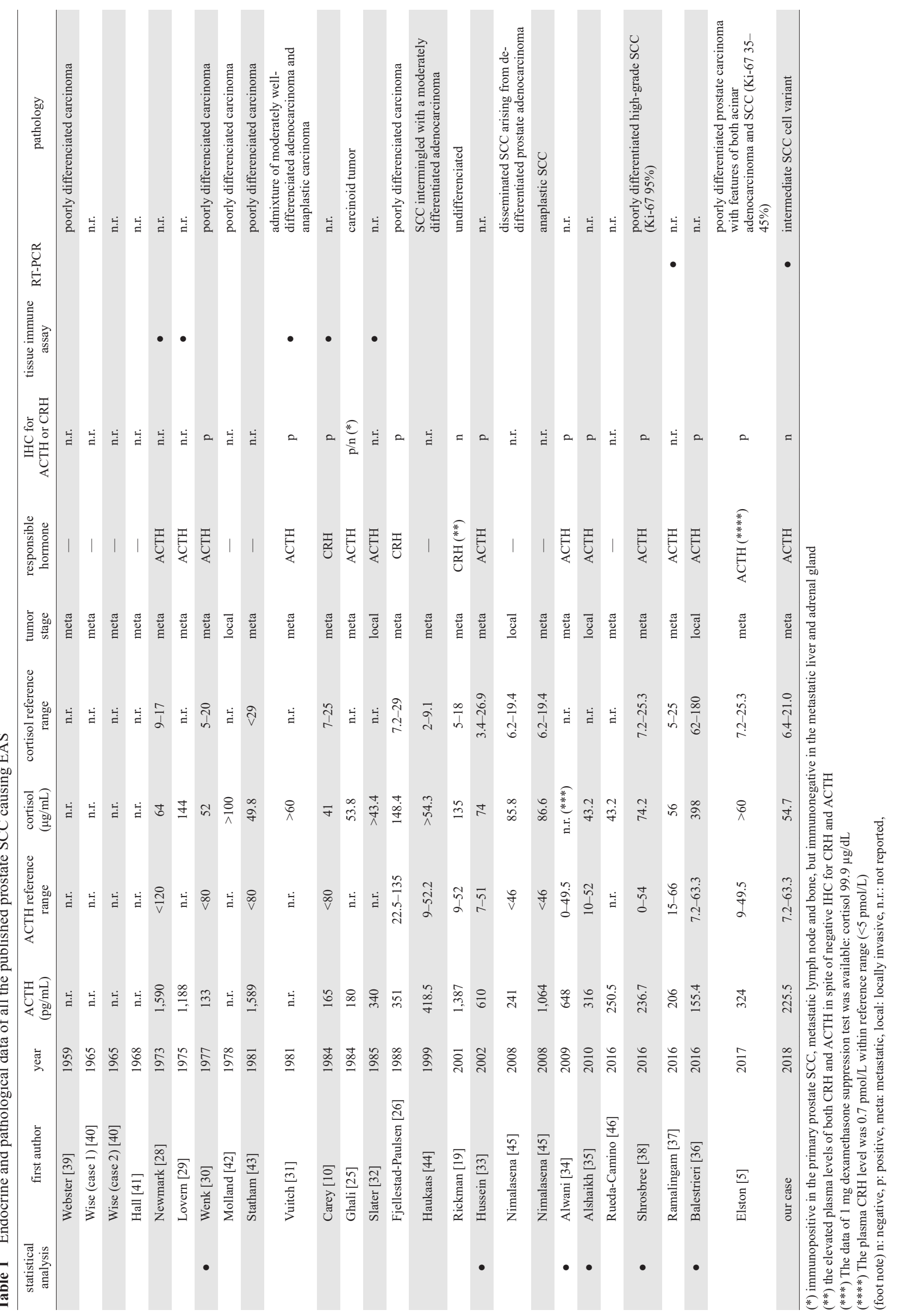




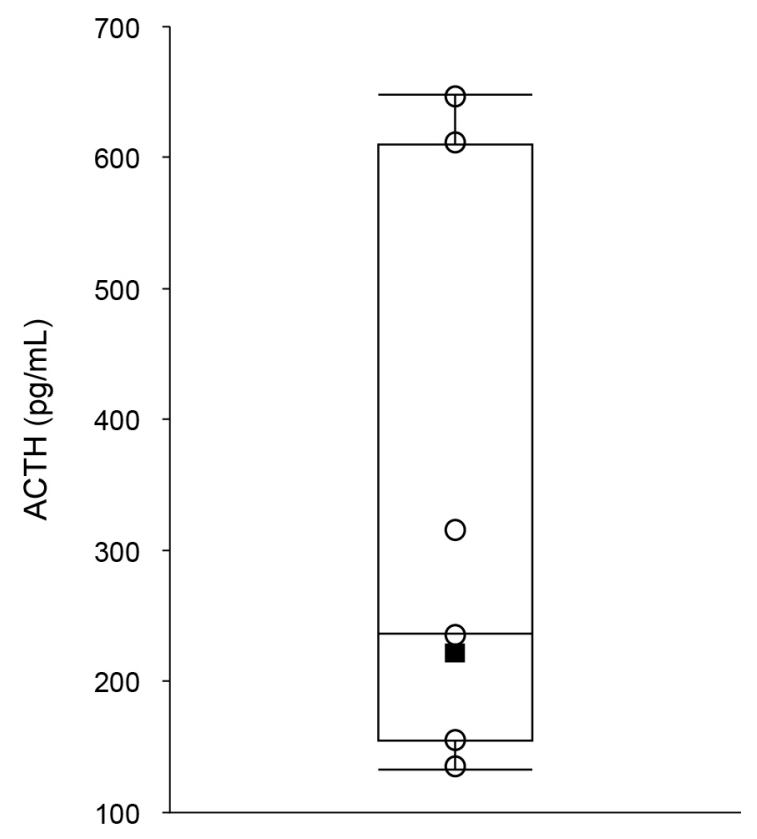

Fig. 4 The analysis of the plasma ACTH level in our case by targeting all the published prostate $\mathrm{SCC}$ cases

In a boxplot, the interquartile range (IQR) and the highest and lowest occurring value are indicated by the box and whiskers, respectively. Open circles point out each plasma ACTH level of 6 cases and a closed square does the plasma ACTH level of our case.

Among the three cases for which reference was made to ectopic CRH secretion [10, 20, 27], Rickman and colleagues attributed elevated plasma levels of both CRH and $\mathrm{ACTH}$ in their case to ectopic CRH secretion despite the negative IHC results for $\mathrm{CRH}$ and $\mathrm{ACTH}$ [20]. In 13 of the prior cases, ACTH was confirmed to be the cause of Cushing's syndrome [5, 22, 26, 28-37] whereas this information was not documented in the remaining 10 cases [38-45]. In 4 of the 13 documented cases, the detection of ACTH was confirmed only by tissue immunoassay $[28,29,32]$ or by the expression of POMC mRNA [36]. In the remaining 9 cases, the presence of ACTH was established by IHC, although this immunoreactivity was absent in the specimens of the metastatic liver and adrenal gland of one of these cases [26]. Disappointingly however, no previous report has provided detailed information on the anti-ACTH antibodies used for immunostaining. Our present case is the first, to our knowledge, to show negative immunostaining for ACTH in spite of the detectable POMC mRNA in the primary lesion among all of the published cases of prostate SCC with Cushing's syndrome to date.

Based on the immunoreactivity with anti-ACTH/ POMC antibodies for our patient's specimens, aberrant prohormone POMC processing might not be a main reason for immunonegativity. We speculated as to why the tumor cells of our patient were so deficient in POMC/ $\mathrm{ACTH}$ that the IHC signals for these proteins were largely undetectable. A rapid secretion theory has been suggested in many prior studies [14, 18-25]. It is postulated in these reports that tumors showing a high secretory rate of ACTH become depleted of its intracellular concentration, resulting in negative immunostaining results on histopathological analysis. This hypothesis originated from a previous study in which immunostaining signals for various kinds of hormone were compared to the histological and clinical observations for 18 EAS cases [13]. Based on our analysis showing that the ACTH level in our case was comparable with those reported for previous immunopositive prostate EAS cases however, we propose that not only rapid ACTH secretion, but also low ACTH synthesis may have played a role in the falsenegative immunostaining findings for our current patient.

This analysis had several limitations. The ACTH assays may have differed between the studies, thereby introducing a possible bias into the results. Moreover, the patients described by Coates and colleagues showed a diverse tumor histology from lung carcinoid, pheochromocytoma, pancreas neuroendocrine tumor to lung SCC, and various cancer stages from early stage to advanced [13]. In contrast, the 26 prior EAS cases were all advanced prostate SCC patients. However, the detailed clinical stages differed among these cases in terms of locally invasive or metastatic disease, resulting in a sample bias. It must be noted also that not all prostate SCC with EAS cases will have been reported in the literature, which would lead to a selection bias. We also cannot exclude the possibilities of a co-secretion of CRH or that negative immunostaining would have been found for some of the previous metastatic lesions in which IHC was not performed i.e. a sample bias. In addition to these possible biases, the current sample number for this condition is still too small to draw robust conclusions. However, given the rarity of prostate SCC with EAS, we believe that our current study provides some important new insights regarding ACTH immunonegativity as we reviewed all of the previously reported cases of this disorder.

A negative ACTH staining result in ectopic tumor tissue has been believed to be associated with a more aggressive disease course and a poorer prognosis, i.e. there is a negative correlation between the extent of malignancy and ACTH immunoreactivity level [22]. Less differentiated tumor cells are likely to lose their hormone synthesis ability, as indicated in previous studies $[46,47]$. Notably, all six immunonegative cases from the Coates study showed a far greater tumor burden with metastasis, which is compatible with greater dedifferentiation [13]. The plasma ACTH levels would 
increase as a whole with a higher tumor burden, even if the tumor cells had a reduced ACTH synthesis capacity reflected in the negative immunostaining finding for this protein. Moreover, rapid ACTH secretion may not reflect tumor activity but an immature secretion machinery, which could be the result of de-differentiation. Dedifferentiated tumor cells may also lose the ability to accumulate ACTH in the secretory granules, resulting in uncontrollable ACTH secretion. Negative immunostaining in metastatic lesions accompanied by advanced disease is therefore compatible with a de-differentiation mechanism [24, 26]. Moreover, decreased immunoreactivity for chromogranin A in our current case (Fig. 1d) might also be a sign of de-differentiation [48].

\section{Conclusion}

We here describe the first case of EAS due to a prostate SCC that showed a negative immunostaining result for ACTH despite the detectable expression of POMC mRNA in the primary lesion. The loss of intracellular ACTH due to a reduced synthesis activity as well as rapid secretion, possibly as a consequence of dedifferentiation, might be the mechanism underlying this ACTH immunonegative finding.

\section{Acknowledgments}

We appreciate Makiko Eda-Hashimoto, Aiko Nishimoto and Kei Sakuma for their technical supports.

\section{Disclosure}

Funding: This work was supported by a grant-in-aid for scientific research from the Ministry of Education, Science, Sports, and Culture, Japan (16K09797).

Conflict of Interest: The authors declare that they have no conflicts of interest with the contents of this article.

\section{References}

1. Ilias I, Torpy DJ, Pacak K, Mullen N, Wesley RA, et al. (2005) Cushing's syndrome due to ectopic corticotropin secretion: twenty years' experience at the National Institutes of Health. J Clin Endocrinol Metab 90: 4955-4962.

2. Mugharbil ZH, Tannenbaum M, Schapira H (1987) Retroperitoneal malignant fibrous histiocytoma: case report and literature review. Mt Sinai J Med 54: 158-161.

3. Walenkamp AM, Sonke GS, Sleijfer DT (2009) Clinical and therapeutic aspects of extrapulmonary small cell carcinoma. Cancer Treat Rev 35: 228-236.

4. Feffer JB, Branis NM, Albu JB (2018) Dual paraneoplastic endocrine syndromes heralding onset of extrapulmonary small cell carcinoma: a case report and narrative review. Front Endocrinol (Lausanne) 9: 170.

5. Elston MS, Crawford VB, Swarbrick M, Dray MS, Head M, et al. (2017) Severe Cushing's syndrome due to small cell prostate carcinoma: a case and review of literature. Endocr Connect 6: R80-R86.

6. Brennan SM, Gregory DL, Stillie A, Herschtal A, Mac Manus M, et al. (2010) Should extrapulmonary small cell cancer be managed like small cell lung cancer? Cancer 116: 888-895.

7. Whitaker DA Jr, Miller DH, Jagadesh N, Strong GW, Hintenlang L, et al. (2016) Small cell carcinoma of the prostate in an elderly patient: a case report and review of the literature. Rare Tumors 8: 6657.

8. Furtado P, Lima MV, Nogueira C, Franco M, Tavora F (2011) Review of small cell carcinomas of the prostate. Prostate Cancer 2011: 543272.

9. Abusnina W, Auyoung EY, Megri M, Pacioles T (2018) Small cell carcinoma of prostate: a case report of a patient with concomitant transitional cell cancer of the bladder.
$J$ Investig Med High Impact Case Rep 6: 2324709618760644.

10. Carey RM, Varma SK, Drake CR Jr, Thorner MO, Kovacs $\mathrm{K}$, et al. (1984) Ectopic secretion of corticotropinreleasing factor as a cause of Cushing's syndrome. A clinical, morphologic, and biochemical study. $N$ Engl J Med 311: $13-20$.

11. Shahani S, Nudelman RJ, Nalini R, Kim HS, Samson SL (2010) Ectopic corticotropin-releasing hormone (CRH) syndrome from metastatic small cell carcinoma: a case report and review of the literature. Diagn Pathol 5: 56.

12. Tsuchiya $\mathrm{K}$, Minami I, Tateno T, Izumiyama H, Doi M, et al. (2005) Malignant gastric carcinoid causing ectopic ACTH syndrome: discrepancy of plasma ACTH levels measured by different immunoradiometric assays. Endocr J 52: 743-750.

13. Coates PJ, Doniach I, Howlett TA, Rees LH, Besser GM (1986) Immunocytochemical study of 18 tumours causing ectopic Cushing's syndrome. J Clin Pathol 39: 955-960.

14. Colleran KM, Burge MR, Crooks LA, Dorin RI (1997) Small cell carcinoma of the vagina causing Cushing's syndrome by ectopic production and secretion of ACTH: a case report. Gynecol Oncol 65: 526-529.

15. Taliouri E, Vrekoussis T, Vergetaki A, Agorastos T, Makrigiannakis A (2013) Corticotropin-releasing hormone $(\mathrm{CRH})$ is expressed in the human cervical carcinoma cells (HeLa) and upregulates the expression of Fas ligand. Tumour Biol 34: 125-130.

16. Messager M, Carriere C, Bertagna X, de Keyzer Y (2006) RT-PCR analysis of corticotroph-associated genes expression in carcinoid tumours in the ectopic-ACTH syndrome. Eur J Endocrinol 154: 159-166. 
17. Stewart PM, Gibson S, Crosby SR, Penn R, Holder R, et al. (1994) ACTH precursors characterize the ectopic ACTH syndrome. Clin Endocrinol (Oxf) 40: 199-204.

18. Wajchenberg BL, Mendonca B, Liberman B, Adelaide M, Pereira A, et al. (1995) Ectopic ACTH syndrome. J Steroid Biochem Mol Biol 53: 139-151.

19. Migueles S, Thompson S, McGrade S (1998) Hyperadrenocorticism in a patient with esophageal squamous-cell carcinoma. Ann Intern Med 128: 157.

20. Rickman T, Garmany R, Doherty T, Benson D, Okusa MD (2001) Hypokalemia, metabolic alkalosis, and hypertension: Cushing's syndrome in a patient with metastatic prostate adenocarcinoma. Am J Kidney Dis 37: 838-846.

21. Miehle K, Tannapfel A, Lamesch P, Borte G, Schenker E, et al. (2004) Pancreatic neuroendocrine tumor with ectopic adrenocorticotropin production upon second recurrence. J Clin Endocrinol Metab 89: 3731-3736.

22. Alwani RA, Neggers SJ, van der Klift M, Baggen MG, van Leenders GJ, et al. (2009) Cushing's syndrome due to ectopic ACTH production by (neuroendocrine) prostate carcinoma. Pituitary 12: 280-283.

23. Cassarino MF, Ambrogio AG, Pagliardini L, De Martin M, Barresi V, et al. (2012) ACTH-secreting pheochromocytoma with false-negative ACTH immunohistochemistry. Endocr Pathol 23: 191-195.

24. Dacruz T, Kalhan A, Rashid M, Obuobie K (2016) An ectopic ACTH secreting metastatic parotid tumour. Case Rep Endocrinol 2016: 4852907.

25. Perez-Rivas LG, Osswald A, Knosel T, Lucia K, Schaaf C, et al. (2017) Expression and mutational status of USP8 in tumors causing ectopic ACTH secretion syndrome. Endocr Relat Cancer 24: L73-L77.

26. Ghali VS, Garcia RL (1984) Prostatic adenocarcinoma with carcinoidal features producing adrenocorticotropic syndrome. Immunohistochemical study and review of the literature. Cancer 54: 1043-1048.

27. Fjellestad-Paulsen A, Abrahamsson PA, Bjartell A, Grino M, Grimelius L, et al. (1988) Carcinoma of the prostate with Cushing's syndrome. Acta Endocrinol (Copenh) 119: 506-516.

28. Newmark SR, Dluhy RG, Bennett AH (1973) Ectopic adrenocorticotropin syndrome with prostatic carcinoma. Urology 2: 666-668.

29. Lovern WJ, Fariss BL, Wettlaufer JN, Hane S (1975) Ectopic ACTH production in disseminated prostatic adenocarcinoma. Urology 5: 817-820.

30. Wenk RE, Bhagavan BS, Levy R, Miller D, Weisburger W (1977) Ectopic ACTH, prostatic oat cell carcinoma, and marked hypernatremia. Cancer 40: 773-778.

31. Vuitch MF, Mendelsohn G (1981) Relationship of ectopic ACTH production to tumor differentiation: a morphologic and immunohistochemical study of prostatic carcinoma with Cushing's syndrome. Cancer 47: 296-299.

32. Slater D (1985) Carcinoid tumour of the prostate associated with inappropriate ACTH secretion. $B r J$ Urol 57: 591-592.

33. Hussein WI, Kowalyk S, Hoogwerf BJ (2002) Ectopic adrenocorticotropic hormone syndrome caused by metastatic carcinoma of the prostate: therapeutic response to ketoconazole. Endocr Pract 8: 381-384.

34. Alshaikh OM, Al-Mahfouz AA, Al-Hindi H, Mahfouz AB, Alzahrani AS (2010) Unusual cause of ectopic secretion of adrenocorticotropic hormone: Cushing syndrome attributable to small cell prostate cancer. Endocr Pract 16: 249-254.

35. Balestrieri A, Magnani E, Nuzzo F (2016) Unusual Cushing's syndrome and hypercalcitoninaemia due to a small cell prostate carcinoma. Case Rep Endocrinol 2016: 6308058 .

36. Ramalingam S, Eisenberg A, Foo WC, Freedman J, Armstrong AJ, et al. (2016) Treatment-related neuroendocrine prostate cancer resulting in Cushing's syndrome. Int J Urol 23: 1038-1041.

37. Shrosbree J, Pokorny A, Stone E, Epstein R, McCormack A, et al. (2016) Ectopic Cushing syndrome due to neuroendocrine prostatic cancer. Intern Med J 46: 630-632.

38. Webster GD Jr, Touchstone JC, Suzuki M (1959) Adrenocortical hyperplasia occurring with metastatic carcinoma of the prostate: report of a case exhibiting increased urinary aldosterone and glucocorticoid excretion. $J$ Clin Endocrinol Metab 19: 967-979.

39. Wise HM Jr, Pohl AL, Gazzaniga A, Harrison JH (1965) Hyperadrenocorticism associated with "Reactivated" prostatic carcinoma. Surgery 57: 655-664.

40. Hall TC (1968) Symptomatic hypokalemic alkalosis in hyperadrenocorticism secondary to carcinoma of the prostate. Cancer 21: 190-192.

41. Molland EA (1978) Prostatic adenocarcinoma with ectopic ACTH production. Br J Urol 50: 358.

42. Statham BN, Pardoe TH, Mir MA (1981) Response of ectopic prostatic ACTH production to metyrapone. Postgrad Med J 57: 467-468.

43. Haukaas SA, Halvorsen OJ, Nygaard SJ, Paus E (1999) Cushing's syndrome in prostate cancer. An aggressive course of prostatic malignancy. Urol Int 63: 126-129.

44. Nimalasena S, Freeman A, Harland S (2008) Paraneoplastic Cushing's syndrome in prostate cancer: a difficult management problem. BJU Int 101: 424-427.

45. Rueda-Camino JA, Losada-Vila B, De Ancos-Aracil CL, Rodriguez-Lajusticia L, Tardio JC, et al. (2016) Small cell carcinoma of the prostate presenting with Cushing syndrome. A narrative review of an uncommon condition. Ann Med 48: 293-299.

46. Grossman AB, Kelly P, Rockall A, Bhattacharya S, McNicol A, et al. (2006) Cushing's syndrome caused by an occult source: difficulties in diagnosis and management. Nat Clin Pract Endocrinol Metab 2: 642-647.

47. Alexandraki KI, Grossman AB (2010) The ectopic ACTH syndrome. Rev Endocr Metab Disord 11: 117-126.

48. Kashiwagi K, Ishii J, Sakaeda M, Arimasu Y, Shimoyamada H, et al. (2012) Differences of molecular expression mechanisms among neural cell adhesion molecule 1, synaptophysin, and chromogranin A in lung cancer cells. Pathol Int 62: 232-245. 